\title{
Enrichissement en acides gras polyinsaturés : étude de la sélectivité des enzymes
}

Oléagineux, Corps Gras, Lipides. Volume 7, Numéro 1, 109, Janvier - Février 2000, Dossier : actes des Journées Chevreul "Corps gras, nutrition et santé, questions d'actualité" (Bordeaux, Pessac)

Auteur(s) : Murielle SCHMITT-ROZIERS, Valérie DEYRIS, Louis-Claude COMEAU, Laboratoire de chimie biologique appliquée, Faculté des sciences et techniques de Saint-Jérôme, Case 431, avenue Escadrille-Normandie-Niemen, 13937 Marseille Cedex 20.

\section{ARTICLE}

Sur le plan biologique, les acides gras polyinsaturés sont extrêmement importants. La biosynthèse des prostaglandines a lieu à partir des acides gras essentiels comme les acides linoléique et alphalinolénique et conduit à la formation d'acides intermédiaires tels que les acides éicosapentaénoïque (EPA) et docosahexaénoïque (DHA). Les acides éicosapentaénoïque et docosahexaénoïque, dérivés de l'acide alpha-linolénique, ont une action fluidifiante sur le sang et sont recommandés dans les maladies cardio-vasculaires et le psoriasis. Chez le fœtus et le nourrisson, leur rôle dans le développement du cerveau et de la rétine est primordial. Le dysfonctionnement de certaines enzymes, en particulier la delta- 6 désaturase, conduit à l'arrêt de la biosynthèse d'acides gras polyinsaturés supérieurs. Pour pallier ce dysfonctionnement, il est donc absolument nécessaire d'avoir un apport exogène en ces acides polyinsaturés en cas de carence. Ainsi des pourcentages élevés en ces acides gras sont parfois nécessaires pour des préparations pharmaceutiques, cosmétiques ou alimentaires. Des recherches effectuées au laboratoire ont montré que certaines lipases présentent une sélectivité vis-à-vis d'acides gras ayant une double liaison proche du groupe carboxyle. Nous avons donc étudié la possibilité d'enrichir des fractions lipidiques en acides gras polyinsaturés particuliers tels que le DHA et I'EPA. Dans ce but, nous nous sommes intéressés à l'estérification biocatalysée par les lipases.

Pour cela, nous avons testé des lipases commerciales issues de Candida rugosa ou Rhizopus arrhizus et le Lipozyme. L'immobilisation de la lipase de Candida rugosa sur résine IRC50 a conduit à une modification de la sélectivité de l'enzyme vis-à-vis de certains acides gras. La sélectivité de ce complexe enzyme-support n'est pas la même que celle observée avec le Lipoyome vis-à-vis du DHA et de I'EPA. Ces sélectivités différentes, selon les biocatalyseurs utilisés, nous ont ainsi permis d'obtenir des fractions enrichies en acide docosahexaénoïque ou éicosapentaénoïque. 